Ю. Н. Варфоломеева. Критерий частотности в исследовании семантики глагольных предикатов описательных текстов

Научная статья

УДК 81 '42

DOI 10.18101/2686-7095-2021-2-11-15

\title{
КРИТЕРИЙ ЧАСТОТНОСТИ В ИССЛЕДОВАНИИ СЕМАНТИКИ ГЛАГОЛЬНЫХ ПРЕДИКАТОВ ОПИСАТЕЛЬНЫХ ТЕКСТОВ
}

\author{
(C) Варфоломеева Юлия Николаевна \\ кандидат филологических наук, доцент, \\ Восточно-Сибирский государственный университет технологий и управления \\ Россия, 670013, Республика Бурятия, г. Улан-У дэ, ул. Ключевская, 40В \\ yulvar83@mail.ru
}

Аннотация. В работе предлагается исследование семантики глагольных предикатов, функционирующих в описательном тексте художественного, нехудожественных книжных (научного, официально-делового, публицистического) и разговорного стилей, с использованием критерия частотности. Классификация глагольных предикатов предполагает выделение в их составе акциональных/неакциональных и эксплицитных/имплицитных единиц с последующей более дробной их классификацией. Применение критерия частотности перечисленных лексико-семантических групп глагольных предикатов позволяет прийти к ряду выводов, касающихся не только наибольшей востребованности тех или иных моделей лексико-семантических групп в описании в целом, но и в разрезе его функционально-стилистической и жанровой парадигм, а также в русле исследования манеры письма каждого отдельного автора. Так, в художественном стиле доминируют зрительные предикаты свето-, цветообозначений и слуховые, в книжных стилях — зрительные предикаты размещения и слуховые. В разговорном описании в высшей степени продуктивны предикаты размещения и обонятельной рецептивной характеристики.

Ключевые слова: текст типа «описание», частотность, функционально-смысловой подход, семантика, глагольный предикат, категория пространства, классификация предикатов, рецептивный, эксплицитный, имплицитный

\section{Для цитирования}

Ю. Н. Варфоломеева. Критерий частотности в исследовании семантики глагольных предикатов описательных текстов // Вестник Бурятского государственного университета. Филология. 2021. Вып. 2. С. 11-15.

Благодарности. Исследование выполнено при финансовой поддержке гранта молодых ученых Восточно-Сибирского государственного университета технологий и управления - 2021. Проект «От субъектной перспективы к субъектной навигации текста».

Исследования текста, привлекающие внимание лингвистов на протяжении многих лет, не теряют своей актуальности и по сей день. Среди разнообразнейших подходов к изучению текста следует выделить функциональносемантический, получивший теоретическую разработку в трудах О. А. Нечаевой и ее последователей [8; 7; 11 и др.].

В соответствии с функционально-смысловым подходом на логической основе выделяются типы речи: описание, повествование, рассуждение. Квалифицируя описание как тип текста, в основе которого лежит перечисление синхронно су- 
ществующих признаков предмета [8, с. 94], заметим, что пространственная семантика выступает основой текста данного типа. Значение пространства, в частности, передается семантикой глагольных предикатов, объединенных общим бытийным значением, выступающим для описания инвариантным [7, с. 21].

На основе наблюдения над описаниями, извлеченными из текстов разных функциональных стилей, была разработана классификация предикатов, функционирующих в описании, в которой глагольные единицы делятся на акциональные/неакциональные, эксплицитные/имплицитные.

С категорией пространства связываются в первую очередь единицы, реализующие зрительную модальность (эксплицитные предикаты), однако в силу того, что пространственное различение осуществляется всеми сенсорными системами [2; 1 и др.], пространственное значение может быть реализовано в описании предикатами выражения других модальностей (слуховыми, обонятельными, вкусовыми, тактильными, недифференцированными). Подобные единицы, выражающие значение пространства в оппозиции «далеко/близко» с точки зрения воспринимающего субъекта, могут быть названы имплицитными предикатами. Акциональные предикаты тоже могут быть обозначены как имплицитное средство передачи пространственной семантики в описательном тексте, поскольку в контексте описания они теряют значение действия, приобретая семантику признака [4].

Классификация предикатов описания может быть представлена на рисунке.

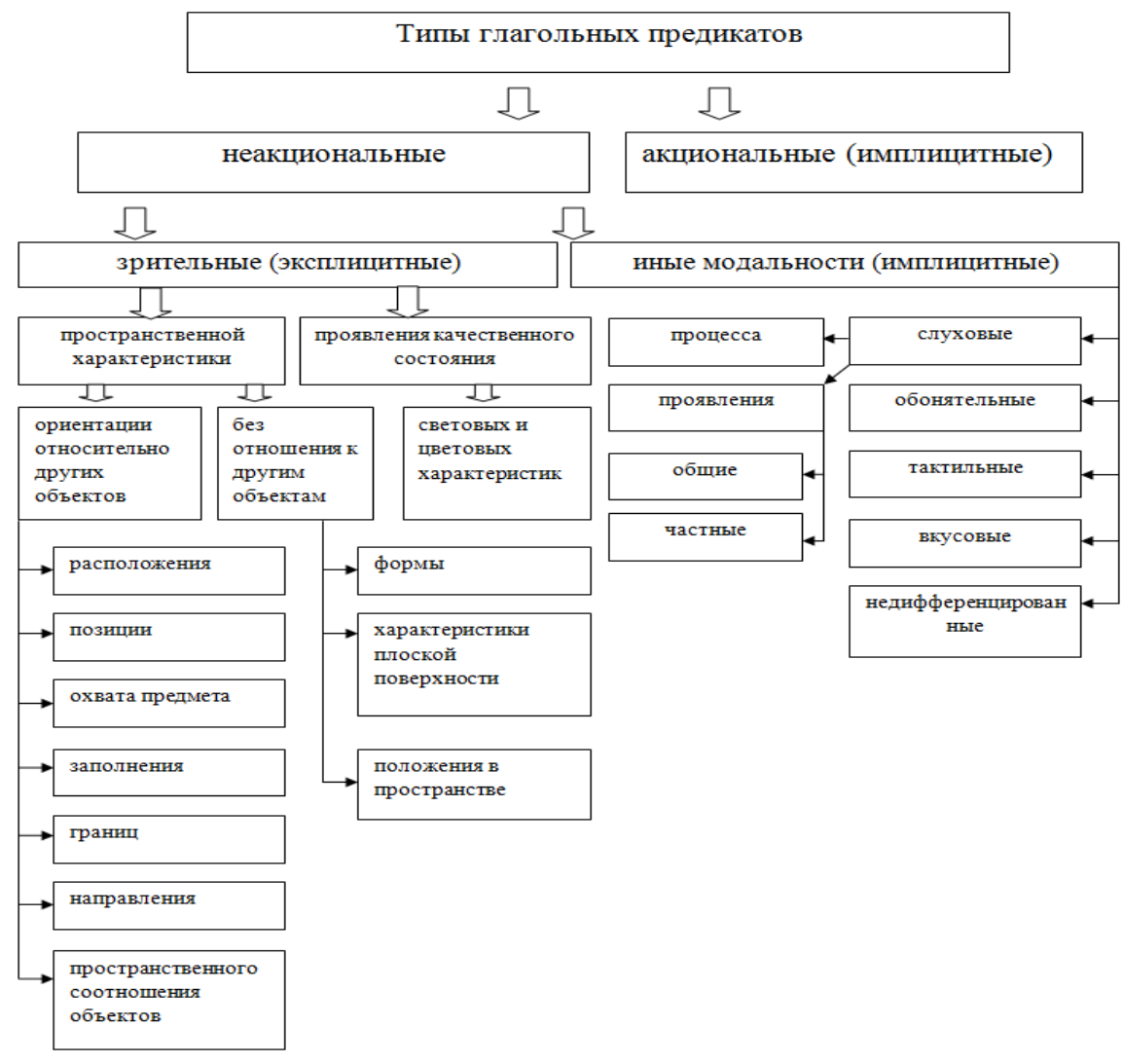

Рис. Классификация глагольных предикатов описательных текстов 
Ю. Н. Варфоломеева. Критерий частотности в исследовании семантики глагольных предикатов описательных текстов

Наполнение каждой лексико-семантической группы (ЛСГ) предикатов разнится в зависимости от стиля. Описание представлено в текстах разных функциональных стилей: художественном (допускающем использование экспрессивных, окказиональных единиц, а также стилистически ограниченных), нехудожественных книжных (научном и официально-деловом, где активно используются нейтральные, специализированные для каждой области знания предикаты; публицистическом, в котором функционируют и терминологизированные, и экспрессивные единицы), разговорном (востребованы разговорные, экспрессивные предикаты).

Анализ частотности перечисленных групп предикатов позволяет сделать ряд выводов, касающихся не только наибольшей востребованности одних или других моделей ЛСГ в разрезе описания в целом, но и его функциональностилистической и жанровой парадигм, а также в русле исследования манеры письма каждого отдельного автора.

Так, в целом наиболее часто для вербализации пространственной семантики в описательных текстах разных функциональных стилей используются эксплицитные неакциональные предикаты зрительной рецептивной характеристики. Если общее число исследованных глагольных предикатов с пространственным значением составляет 4300 , то количество единиц зрительной рецептивной характеристики - 3667, предикатов представления слуховой, обонятельной, вкусовой, тактильной и недифференцированной рецептивных характеристик - 457, акциональных - 176. Это подтверждает мысль о наибольшей роли зрительного восприятия.

В художественном стиле самой частотной ЛСГ выступает группа предикатов проявления качественного состояния объекта, а именно его свето- и цветохарактеристик (светиться, розоветь, поблескивать и др.). Вероятнее всего, «игра»с цветом помогает в художественном тексте отобразить авторское видение мира, оказывается значимой для разных жанров описания, «цветопись» может приобретать символический смысл. При этом творческая манера каждого отдельного писателя также может быть рассмотрена в этом аспекте. Так, например, в прозе известного сибирского писателя И. К. Калашникова явно доминируют предикаты цвета/света, составляя почти $40 \%$ от всех единиц зрительной рецепции. Каждое второе описание автора изобилует предикатами указанной группы, кроме того, он использует и окказиональные единицы данной ЛСГ (лищо осмуглено, дорога отглянцована и др.) [3].

Указанное выше объясняет особое внимание ученых к изучению роли цвета в художественном тексте [5; 6; 10 и др.]. Так, И. Г. Оконешникова отмечает, что «взаимодействие доминирующих модусов перцепции в сознании автора создает определенную стратегию реализации авторского замысла» [9, с. 3].

Относительно исследования частотности употребления в описательном тексте глагольных предикатов слуховой, обонятельной, вкусовой, тактильной и недифференцированной рецептивных характеристик в художественном стиле заметим, что наиболее активно используются единицы слуховой модальности, что коррелирует с общими положениями теории восприятия.

В книжных описаниях из эксплицитных рецептивных предикатов преобладают единицы размещения, это может быть объяснено тем, что в текстах подобного рода значимым является только обозначение «присутствия» объекта в описываемом пространстве (например, в протоколах осмотра места происшествия, ис- 
следования по астрономии, проектах организации строительства и др.). Из имплицитных рецептивных предикатов доминируют слуховые.

Разговорная речь при значительной доле слуховых предикатов характеризуется наибольшей частотой употребления единиц обонятельной рецептивной характеристики. Что же касается зрительных предикатов, то наиболее употребительны единицы размещения. Вероятно, подобная специфика отражает отсутствие необходимости указывать те или иные свойства пространства в ситуации живого общения, когда есть возможность использования паралингвистических средств для передачи зрительно или аудиально воспринимаемых свойств описываемого пространства при полном отсутствии таковой для характеристики ольфакторного состояния среды.

В жанровом отношении описание может быть дифференцировано по типам: описание-пейзаж, описание-интерьер, описание-портрет и описание предмета. Наибольшее разнообразие предикатов (и эксплицитных, и имплицитных) наблюдается в описании-пейзаже. Для описания-интерьера можно отметить более ограниченный в сравнении с пейзажем набор предикатов, в данном случае высока частотность позиционных предикатов и предикатов заполнения пространства, что обусловлено спецификой самого объекта описания (наполнение помещения предметами). Минимален набор пространственных предикатов в описаниипортрете при доминировании единиц характеристики формы предмета (специфика внешности человека делает востребованной данную ЛСГ предикатов для описания формы прически, глаз, губ и т. д.). Обобщение особенностей функционирования описания предмета затруднительно, поскольку предметом могут быть названы совершенно разные материальные сущности.

Таким образом, применение критерия частотности исследованных ЛСГ пространственных глагольных предикатов позволяет говорить о продуктивности тех или иных моделей ЛСГ не только в описании в целом, но и в разрезе его функционально-стилистической и жанровой парадигм, а также в русле исследования манеры письма каждого отдельного автора.

Литература

1. Ананьев Б. Г. Психология и проблемы человекознания. Избранные психологические труды / под редакцией А. А. Бодалева. Москва: Институт практической психологии; Воронеж: МОДЭК, 1996. 384 с. Текст: непосредственный.

2. Бериташвили И. С. Нервные механизмы поведения высших позвоночных животных. Москва: Изд-во АН СССР, 1961. 367 с. Текст: непосредственный.

3. Варфоломеева Ю. Н. Категоризация и концептуализация пространства в описательном тексте // Научный диалог. 2020. № 4. С. 27-39. Текст: непосредственный.

4. Варфоломеева Ю. Н. Глагольные предикаты со значением существования в тексте типа «описание» (на материале произведений И. К. Калашникова) // Интерпретация текста: лингвистический, литературоведческий и методический аспекты: материалы I Международной научной конференции. Чита, 2007. С. 22-24. Текст: непосредственный.

5. Верескун С. А. Ассоциативно-смысловое поле цвета в прозе М. И. Цветаевой: диссертация на соискание ученой степени кандидата филологических наук. Ростов-на-Дону, 2012. 276 с. Текст: непосредственный.

6. Ермакова О. Б. Концептуализация цвета в русском языке: диссертация на соискание ученой степени кандидата филологических наук. Москва, 2007. 345 с. Текст: непосредственный.

7. Коньков В. И., Неупокоева О. В. Функциональные типы речи: учебное пособие. Москва: Академия, 2011. 224 с. Текст: непосредственный. 
Ю. Н. Варфоломеева. Критерий частотности в исследовании семантики глагольных предикатов описательных текстов

8. Нечаева О. А. Функционально-смысловые типы речи (описание, повествование, рассуждение). Улан-Удэ: Бурят. кн. изд-во, 1974. 261 с. Текст: непосредственный.

9. Оконешникова И. Г. Роль модусов перцепции в организации смыслового и коммуникативного пространства художественного прозаического текста (на материале романов Р. Кинга): автореферат диссертации на соискание ученой степени кандидата филологических наук. Омск, 2009. 18 с. Текст: непосредственный.

10. Цегельник И. Е. Цветовая картина мира Иосифа Бродского: когнитивнофункциональный подход: диссертация на соискание ученой степени кандидата филологических наук. Ростов-на-Дону, 2007. 157 с. Текст: непосредственный.

11. Чебанов С. В., Мартыненко Г. Я. Семиотика описательных текстов: типологический аспект. Санкт-Петербург: Изд-во СПбГУ, 1999. 424 с. Текст: непосредственный.

Статья поступила в редакцию 24.02.2021; одобрена после рецензирования 30.05.2021; принята к публикации 30.06.2021.

\section{WORD FREQUENCY CRITERION IN STUDY OF VERB PREDICATES SEMANTICS OF DESCRIPTIVE TEXTS}

Yulia N. Varfolomeeva

Cand. Sci. (Phil.), A/Prof.,

East Siberia State University of Technology and Management

40V Klyuchevskaya St., Ulan-Ude 670013, Russia

yulvar83@mail.ru

Abstract. The article examines the semantics of verb predicates functioning in the descriptive text of fiction and non-fiction (scientific, official, business, journalistic) and colloquial styles, using the criterion of frequency. The classification of verb predicates involves the allocation of actional / non-actional and explicit / implicit units in their composition, followed by their more fractional classification. The use of the frequency criterion of the listed lexical-semantic groups of verb predicates allows to come to a number of conclusions related not only to the greatest demand for certain models of lexical-semantic groups in the description as a whole, but also to the context of its functional, stylistic and genre paradigms, as well as in line with research on the writing style of each individual author. Thus, visual predicates of light and color designations, as well as auditory ones dominate in the artistic style. In book styles, there are visual placement and auditory predicates. In colloquial description, predicates of placement and olfactory receptive characteristics are eminently productive.

Keywords: descriptive text; word frequency; functional and semantic approach; semantics, verb predicate, category of space, predicate classification, receptive predicate; explicit predicate; implicit predicate.

For citation

Varfolomeeva Yu. N. Word Frequency Criterion in Study of Verb Predicates Semantics of Descriptive Texts. Bulletin of Buryat State University. Philology. 2021; 1: 11-15 (In Russ.).

Acknowledgments. The study was carried out with the financial support of a grant from young scientists of the East-Siberian State University of Technology and Management 2021. Project "From a Subject Perspective to a Subject Text Navigation".

The article was submitted 24.02.2021; approved after reviewing 30.05.2021; accepted for publication 30.06.2021. 